\title{
Evaluation of Indoor Environment in Apartment Buildings Before and After their Refurbishment
}

\author{
Dušan Petráśs ${ }^{1}$, Veronika Földváry ${ }^{2}$, Hana Pustayová Bukovianská ${ }^{3}$ \\ ${ }^{1,2,3}$ Slovak University of Technology in Bratislava
}

\begin{abstract}
The objective of the study is to analyse and evaluate the indoor environment of the apartment buildings before and after their refurbishment. Thermal comfort and indoor air quality were taken into consideration based on both objective and subjective evaluation. Thermal indoor environment was evaluated in six blocks of dwelling buildings situated in Slovakia. Evaluation of the thermal indoor environment was based on the recording of the indoor temperature and the relative humidity before and after refurbishment. The subjective evaluation was based on a questionnaire survey, which includes data such as the thermal perception, inhabitant's behaviour and personal background of 244 respondents living in the buildings before refurbishment and 236 respondents living in the buildings after refurbishment.
\end{abstract}

Keywords - energy retrofitting, thermal comfort, indoor air quality, occupants' behaviour

\section{INTRODUCTION}

Buildings are responsible for a substantial portion of global energy consumption. Most of the multifamily residential buildings in Slovakia built in the 20th century do not satisfy the current requirements for energy efficiency. Nationwide remedial measures are taken to improve the energy efficiency of these buildings and reduce their energy consumption. However, since the impact of these measures on the indoor air quality is rarely considered, they often compromise indoor air quality due to the decreased ventilation and infiltration rate. Poor indoor air quality in dwellings may have adverse effect on the health and comfort of the occupants. The objective of this study was to evaluate the impact of energy renovation on the indoor environmental quality of multifamily apartment buildings (Földváry et al., 2014).

The Slovak housing stock is young compared to the housing stock in other European countries, but it is characterised by poor quality of construction and inadequate maintenance. The situation in the housing sector in Slovakia has been changing seriously during the past 15 years. The new housing production has decreased considerably compared to the one before 1990. The highest number of buildings was built in 1970's, when mainly pre-fabricated and pre-stressed concrete buildings were used. Nowadays, they do not comply with the current requirements on thermal protection and energy efficiency of buildings in Slovakia (Pustayová, 2013).

\section{II.THERMAL COMFORT EVALUATION}

The objective of the study is to assess indoor environment in panel buildings before and after their refurbishment and to study occupants' behaviour and their habits. Initial investigation showed that dwelling houses were constructed by using a single technology throughout several decades. In our study, six types of building structural systems were chosen, which are mostly situated in Bratislava, Slovakia (Fig. 1). Building refurbishment included three energy efficiency strategies: thermal insulation of facade and roof, replacement of windows in common premises, balancing of the hydraulic heating system, (Pustayová, 2013).

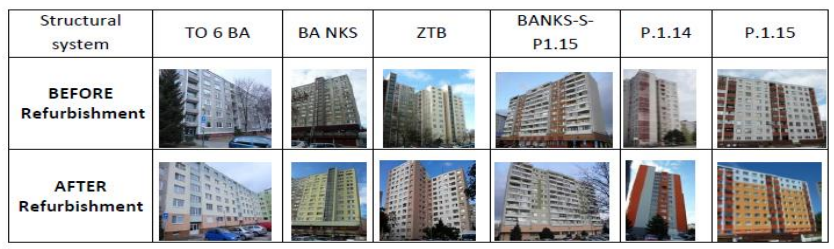

Fig. 1. Building systems for case study before and after the refurbishment.

For the purpose of subjective evaluation, two types of questionnaires were created (questionnaires used before and after refurbishment). The questionnaire revealed the thermal indoor environmental condition based on inhabitants' personal perception. Each questionnaire was divided into four main parts:

- Basic information about inhabitants;

- Building constructions;

- Thermal comfort (general thermal comfort and local thermal discomfort);

- Ventilation habits (Pustayová, 2013).

The evaluation of thermal environment was performed using PMV and PPD indices. The PMV index predicts the mean value of the thermal votes of a large group of people exposed to the same environment on the 7-point thermal sensation scale. The PMV depends on the following six parameters: the occupants' physical activity (metabolic rate); the thermal resistance of their clothing; air temperature; mean radiant temperature; air velocity; partial water vapor pressure (ISO EN 7730). The PPD index establishes a quantitative prediction of the number of thermally dissatisfied people. The PPD predicts the percentage of a large group of people likely to feel too warm or cool, i.e. voting hot $(+3)$, warm $(+2)$, cool $(-2)$ or cold $(-3)$ on the 7-point thermal sensation scale (CEN CR 1752).

The subjective evaluation of the indoor environment was carried out in the middle of the heating season in January of 2012. Inhabitants' responses regarding thermal comfort were analyzed in the buildings using the following parameters: thermal sensation (TS) and thermal acceptability (TA). Fig. 2 presents the responses on thermal sensation and inhabitant's 
perceived temperature in their apartments: before and after refurbishment (Pustayová, 2013).

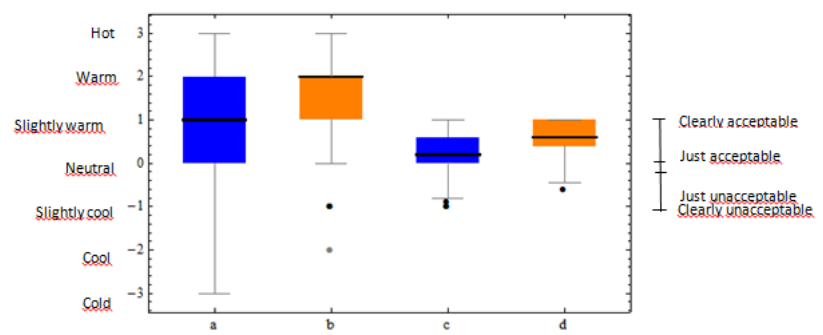

Fig. 2. Evaluation of Thermal Indoor Environment in apartments during the study ( a) Thermal sensation -before refurbishment, b) Thermal sensation after refurbishment, c) Thermal acceptability before refurbishment, d) Thermal acceptability after refurbishment. ).

In the non-refurbished buildings, the TS value was 0.78 and median value was 1 (slightly warm). In the renovated ones, the TS value was 1.36 and median value was 2 (warm). The median value of thermal acceptability before refurbishment was 0.3 while after refurbishment it increased to 0.59 , which is closer to 1 (clearly acceptable thermal environment). In Fig. 3a, the answers were marked on the 7-point thermal sensation scale by the inhabitants of original and renovated buildings. Fig. $3 b$ shows the results of acceptability of thermal environment evaluated also by occupants of both types of buildings.
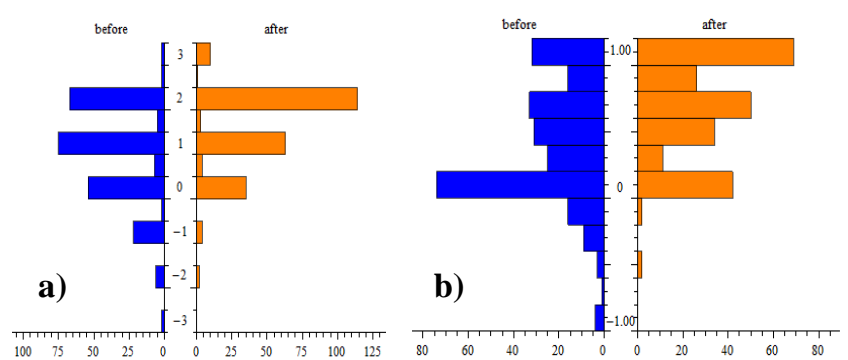

Fig. 3. Comparison of thermal sensation (a) and thermal acceptability (b) in the evaluated buildings.

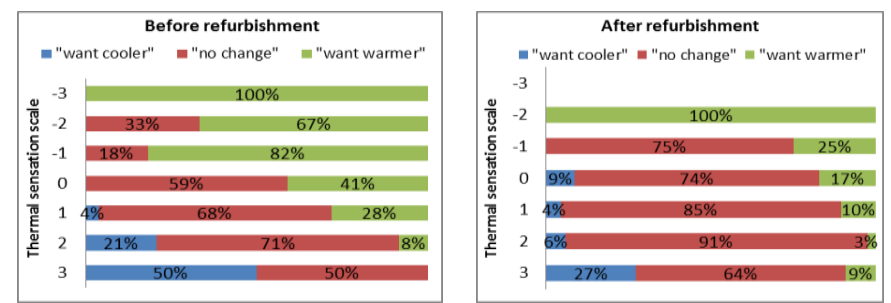

Fig. 4. Distribution of coincident thermal preference and thermal sensation votes.

In both cases, the respondents' neutral preferences are stronger on a cool side rather than on a warm side. In the prerenovated buildings, the respondents' neutral preference is more significant than respondents' preference in buildings after renovation (Fig. 4). Overall, the preferred sensations in the buildings after renovation were in the positive scale of thermal sensation. The majority of the respondents, which voted in the positive range, preferred no changes.

This case study confirmed that inhabitants living in the buildings before renovation prefer higher temperature than the ones living in the renovated buildings. The study showed that the majority of inhabitants used to wear medium clothing, which means 0.6 clo, although typical clothing for winter season is around 1.0 clo, according standard EN 15251. The inhabitants preferred lighter clothing during the heating season. This could explain why occupants in general prefer warmer indoor environment. The clothing adjustment plays an important role in the building energy consumption.

\section{INDOOR AIR QUALITY EVALUATION}

The investigation of indoor air quality was carried out in three pairs of dwellings located in southwest part of Slovakia. One of the buildings in each pair of dwellings has been renovated (thermally insulated façade, replacement of old windows with new energy efficiency windows, hydraulic balancing of the heating system) and the other was in its original state (Földváry et al., 2014).

Experimental measurements were performed during the heating season in 2013/2014. Temperature, relative humidity and the concentration of $\mathrm{CO}_{2}$ were measured in bedrooms of the apartments using a HOBO U12-012 data logger (Onset Computer Corp.,USA) and CARBOCAP $\mathrm{CO}_{2}$ monitors (GMW22, Vaisala, Finland). The data were recorded at 5 minutes intervals for one week in each building (Földváry et al., 2014). The locations of the instruments were selected with respect to the limitations of the carbon dioxide method (Persily, 1997).

Subjective evaluation of perceived air quality was conducted in parallel with experimental measurements of $\mathrm{CO}_{2}$ concentration, indoor air temperature and humidity. The questionnaires contained questions about basic information on the occupants, building characteristics, occupants' behavior and habits, occupants' perception of indoor air quality. The occupants of the renovated buildings were also asked questions about altered ventilation habits after renovation (Földváry et al., 2014).

The winter measurements showed higher average $\mathrm{CO}_{2}$ concentration in the renovated residential buildings. In $80 \%$ of apartments located in the energy retrofitted dwellings, the average $\mathrm{CO}_{2}$ concentration was higher than 1000 ppm, while this was the case in $71 \%$ of the apartments in the original buildings. The results of air change rate calculations show significant differences between the original and retrofitted buildings (Table 1), (Földváry et al., 2014).

\section{TABLE 1}

TEMPERATURE, RELATIVE HUMIDITY, NIGHT-TIME $\mathrm{CO}_{2}$ CONCENTRATIONS, FRACTIONS OF APARTMENTS WITH AVERAGE $\mathrm{CO}_{2}$ ABOVE 1000 PPM AND AER IN ORIGINAL AND RENOVATED BUILDINGS

\begin{tabular}{lcc}
\hline & Original buildings & Renovated buildings \\
\hline Mean temperature $\left({ }^{\circ} \mathrm{C}\right)$ & 21.6 & 23.0 \\
Mean humidity $(\%)$ & 47 & 45 \\
Mean $\mathrm{CO}_{2}$ during night* $(\mathrm{ppm})$ & 1425 & 1680 \\
Average $\mathrm{CO}_{2}>1000 \mathrm{ppm}(\%)$ & 71 & 80 \\
Average AER $\left(\mathrm{h}^{-1}\right)$ & 0.79 & 0.48 \\
\hline
\end{tabular}


Fig. 5a summarizes the occupants' answers to the question "How unpleasant do you think the indoor air quality is in your bedroom during night/in the morning?". The possible answers were from 1 - perceived air quality was not a problem, to 6 poor indoor air quality. While the residents in the nonrenovated building did not indicate severe problems with perceived air quality, a greater fraction of the occupants were dissatisfied with it in the renovated buildings.

Energy renovation of apartment buildings may directly lead to lower ventilation rates and higher concentrations of indoor pollutants (Noris et al, 2013). This is especially the case when the occupants do not alter their ventilation habits after renovation of the building. In the present study, only $22 \%$ of the occupants indicated that they ventilate more often than before renovation (Fig. 5b), (Földváry et al., 2014). a)

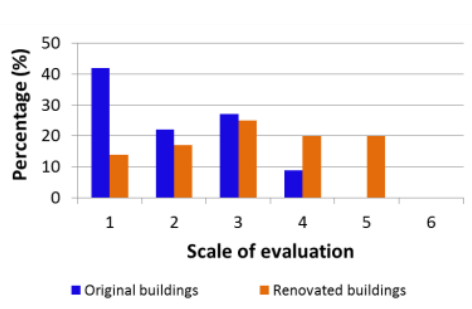

)

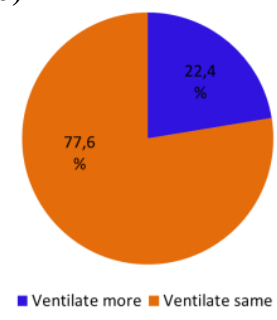

Fig. 5. Summary of subjective evaluation of indoor air quality by one occupant in each of the investigated residential buildings. One occupant in each apartment answered (a); Ventilation habits of occupants in retrofitted buildings (b).

As the results of $\mathrm{CO}_{2}$ concentration and perceived air quality analysis show, renovation of apartment buildings in Slovakia may reduce the quality of indoor air in the apartments. The average concentration of $\mathrm{CO}_{2}$ is visibly higher in the renovated buildings and it does not fulfil the criteria of $1000 \mathrm{ppm}$. Subjective evaluation of indoor air quality showed that only $22 \%$ of the occupants indicated that they ventilate more often than before renovation, which is still not enough to improve the indoor air quality to the level as it was before reconstruction. The final conclusion is that energy retrofitting of apartment buildings in Slovakia may directly lead to lower ventilation rates, higher concentrations of indoor pollutants, especially in the winter season. The current study examines whether large-scale renovations of apartment buildings in Slovakia result in reduced quality of the indoor environment in a substantial fraction of the apartments.

\section{ACKNOWLEDGEMENT}

Thanks are due to the Technical University of Denmark (International Centre for Indoor Environment and Energy). The authors want to thank Bjarne W. Olesen and Gabriel Bekö for co-supervising of the projects.

\section{REFERENCES}

[1] Pustayová H., Petráš, D. Effect of refurbishment on thermal comfort and energy use in residential multifamily building. REHVA European HVAC Journal Vol.49, Iss.6.(2012)s.54-57.

[2] Pustayová H., Petráš, D. 2011 Energy And Environmental Evaluation of A Residential Building Before And After Complex Renovation. In INDOOR AIR 2011: Austin, Texas, 5.-10.6.2011. 2011.

[3] Buildings Performance Institute Europe (BPIE), Europe's Building under the Microscope-a country by country review of the energy performance of buildings, 2011.

[4] EN 15251 Indoor environmental input parameters for design and assessment of energy performance of buildings addressing indoor air quality, thermal environment, lighting and acoustics. Brussels: CEN.

[5] ISO EN 7730 Moderate thermal environments - Determination of the PMV and PPD indices and specification of the conditions for thermal comfort. Geneva: International Standards Organisation.

[6] EN ISO 7726:1998 Ergonomics of the thermal environment -Instruments for measuring physical quantities.

[7] Földváry V., Bekö G., Petráš D. (2014) Impact of energy renovation on indoor air quality in multifamily dwellings in Slovakia. Proceedings of Indoor Air 2014, Hong Kong, Paper No. HP0143.

[8] Földváry V., Petráš D.: Comparison of carbon dioxide concentration and air change rates in two identical dwellings before and after renovation in Slovakia. In E-NOVA 2014: Internationaler Kongress. Nachhaltige Gebäude. ISBN 978-3-7011-0316-4.

[9] Földváry V., Petráš D.: Indoor air quality in apartment buildings in Slovakia and its dependence on renovation. In ROOMVENT 2014 : Proceedings of the 13th SCANVAC International Conference on Air Distribution in Rooms: New ventilations strategies with base in active and passive technology in building and for comfort in airplanes, Sao Paulo, Brazil,19.-22.10.2014. 1. vyd. Sao Paulo: IPT Institutode Pesquisa Tecnologica, 2014, s. 104-109.

[10] Persily, AK., Evaluating Building IAQ and Ventilation with Indoor Carbon Dioxide. ASHRAE Transactions, 1997, Vol. 103, No. 2.

[11] Noris F., Delp W., Vermeer K., Adamkiewicz G., Singer B., Fisk W. Protocol for maximizing energy savings and indoor environmental quality improvements when retrofitting apartments. Energy and Buildings, 2013, vol. 61, p. 378-386. http://dx.doi.org/10.1016/j.enbuild.2013.02.046 